\title{
Study on Ways of Promoting Core Competence of Enterprise through Management Accounting Against the Background of Big Data
}

\author{
Guyin Li, Luo Wang \\ Institute of Finance and Management \\ Chongqing College of Electronic Engineering \\ Chongqing, China \\ Email: 1292297787@qq.com, 470128751@qq.com
}

\begin{abstract}
In the era of big data, the environment of accounting has changed significantly. Companies are urgently required to make better use of management accounting, change the status of financial and business separation of traditional financial accounting, improve the timeliness and usefulness of management decisions, and enhance the company's core competitiveness. Based on this, the paper proposes the path of management accounting to enhance the core competitiveness of enterprises, mainly including building a data management platform, establishing a real-time financial reporting system, and training high-quality management accounting talents.
\end{abstract}

Keywords: Big Data, Management Accounting, Core Competence of Enterprise

\section{INTRODUCTION}

In the era of big data, there are a large number of data and high-speed update, and the limitations of financial accounting are even more prominent. Additionally, traditional financial accounting relies solely on financial data and ignores related information; it reflects the past business activities of company and cannot predict the future well; due to the lags of information disclosure, it does not meet the demand timely and efficiently. Therefore changes of the accounting environment require companies to adapt to the impact of big data, improve the situation of separation and financing and business of traditional financial accounting, enhance the timeliness and usefulness of management decisions as well as the company's core competitiveness.

\section{THE IMPORTANCE OF CORE COMPETENCE FOR ENTERPRISE}

In 1990, Prahalad and Hammer first proposed the concept of "core competence" in the article "Corporate Core Competence" published in the famous Harvard Business Review. They believe that "the core competitiveness is the accumulated knowledge in the organization, especially the knowledge of how to coordinate different production skills and organically combine various technical branches, and the ability of companies to develop unique products, develop unique technologies and invent unique marketing methods".

Additionally, the core competitiveness is a sustainable competitive advantage that can bring unique characteristics and excess profits to the company. Enterprises with core competitiveness also could better adapt to the changes in the external environment, access to a variety of scarce resources and continued competitive advantage to enhance the market competitiveness of enterprises, and then generate excess profits. Besides, under the new economic environment, quality and efficiency are of importance in the creation of corporate value in the fierce market competition, enterprises must pay attention to the improvement of their core competitiveness.

\section{REQUIREMENT OF MANAGEMENT ACCOUNTING TO IMPROVE CORPORATE CORE COMPETITIVENESS IN THE ERA OF BIG DATA}

The core competitiveness of enterprise is not only reflected in products and technologies, but also reflected in the management and decision-making capabilities of the enterprise. In the era of big data, applying the advantages of big data to enterprises must rely on management accounting to collect, analyze, and utilize financial information and non-financial information, to provide decision-relevant information timely, form an effective decision-making capability, and strengthen the core competitiveness and better improve the value creation of the company.

Based on financial accounting support, management accounting information comes from the original information generated in each part of the company's business activities, but the data processing methods are different because of the need of internal management. Furthermore, management accounting requires the support of financial data, but management accounting is not limited to financial data, it also focuses on the collection, organization, and utilization of non-financial data. And these data may appear in the forms of digit, text, and graph, which constitute the data in the perspective of management accounting. Also the quality of various financial and non-financial information in a company's business operations determines its value to corporate managers.

Contribution to improve timeliness and decision-making efficiency. In the era of big data, data processing and updating are fast and short period, and they are more timely and effective, which could satisfy the demand for timeliness of information management accounting. In order to respond to the ever-changing 
market environment, companies must regard "timeliness" as their primary quality requirement. Additionally, management accounting can no longer focus on cost accounting, different kinds of information technology should be applied to management accounting activities to improve the efficiency of decision-making.

Contribution to get more comprehensive data. Big data has the characteristics of mass production, diversification, high-speed, and low value density. And the more comprehensive the data the company uses to analyze, the closer to the truth the results of the analysis. Besides, based on data storage and data mining technology of big data, the data acquisition channel of management accounting extends from the finance department to various business departments. When the management accounting tool is used to analyze and process data, the sample information can be expanded to the overall information, which greatly reduces the impact of accidental errors in the sample survey on the results and makes the management of the company more refined and plays an increasingly important role in the decision-making of the enterprise.

Contribution to enhance decision-making and forecasting. In the context of big data, the value density of data is relatively low but it has relatively high commercial value. Therefore, enterprises should appropriately abandon the accuracy of data, attach importance to the correlation between data, and excavate the data laws contained in big data from the large amount of financial and non-financial data information generated in production and business activities, and find out various data or information that have reference value to economic decisions for managers.

Furthermore, management accounting in the era of big data could obtain data from every process of operation and management, improve the ability of predicting future business trends and development directions, and make more scientific and effective decisions.

\section{PATHS OF PROMOTING CORE COMPETENCE OF ENTERPRISE THROUGH MANAGEMENT ACCOUNTING}

In the context of big data, management accounting, as a supporting decision-making activity for the production and operation of enterprises, could be improved as the external environment changes. Companies also make use of various information technologies of big data, on the basis of understanding individual consumer preferences, fully tap market needs and innovate products or services so that they can survive in the market and cultivate their core competitiveness. Besides, faced with many types and large quantities of information data, management accountants must improve their own quality, rely on platforms to collect, sort and analyze data timely, and then provide data support for decision makers.

Build data management platforms. The data management platform is an integrated technology platform for enterprise management, internal and external customer marketing data management and consumption. The data management platform also integrates distributed multi-party data into a unified technology platform and standardizes and subdivides these data to help managers make accurate decisions. Furthermore, the data management platform mainly has four major functions: data acquisition, data management, data analysis and data application function. Every part is crucial and any data analysis and mining is for practical applications. A good data management platform can run through the entire process of the entire enterprise's management activities and provide information timely and effectively, which helps managers to make accurate decisions to improve core competitiveness.

In addition to, information technology integrates business and finance in the context of big data. Specifically, when the business occurs, event-driven recording services are used. The business-event processor concentrates financial, business, and management information on the data management platform according to certain rules, and when different "authorized" personnel need to use information, they can extract from the data management platform. Besides, the accounting personnel must enter the front end from the post-event report, to enter the management of the basic data, enter the business execution process, and enter the entire business analysis process. And based on the data acquired, accountants use information processing technology to process various financial and non-financial data of enterprises the acquired data scientifically and efficiently. And purifying a large amount of data through data cleansing and mining, and providing financial reports that dynamically meet the needs of companies, helping companies improve management efficiency and accuracy, decision-making, and then enhance the core competitiveness.

Establish a real-time financial reporting system. The modern enterprise management model is constantly refined and in-depth management accounting also need to participate in the company's entire business management process, support product and service innovation, and create value for the company throughout the entire process. Besides, traditional financial reports are compiled after the occurrence of business and events. Therefore, the timeliness is not good enough to meet the needs. As an important support for business decision-making activities, management accounting not only needs to be familiar with the business and operations of the company, but also needs to establish a real-time financial reporting system to timely and comprehensively grasp the various operating conditions of the company, weigh risks and benefits, and reduce the loss generated by inappropriate decision-making.

Facing the fast-change markets, the timeliness and effectiveness of information transfer are particularly important. Under the background of big data, the establishment and use of the data management platform enables various kinds of information of the enterprise to be obtained in real time, and the data is more accurate and comprehensive, which makes real-time financial reports possible. Additionally, through the sorting of various real-time dynamic information of enterprises, data cleaning and mining, establishing a real-time financial reporting system, preparing financial reports of any period 
according to the need, and improving the timeliness of financial reporting.

Training high-quality management accounting talents. In the context of big data, companies rely on data management platforms to process data, and the operation of data management platforms and the normal operation of real-time financial reporting systems are inseparable from management accounting. On the one hand, the data management platform only provides the results of data collation and analysis, and it cannot replace the professional judgement of accounting personnel, management accounting personnel need adequate knowledge of management accounting and continuously improve their professional quality in order to prepare real-time financial reports according to their needs; on the other hand, management accountants need to know how to use big data, and rely on the ability of capturing sensitive information and the work experience of management accounting, to accurately find decision-related information from the massive data to analyze and to predict business operations.

Therefore, in the era of big data, the management accounting work has changed from an auxiliary function to a core function. In order to give full play to the advantages of the big data, management accountants not only need to possess a solid accounting expertise, but also need to be familiar with the business process operations, internal and external value chain activities, and constantly improve the capabilities of data extraction and analysis. Furthermore, the quality and ability need to reach a certain level, providing enterprises with more accurate and more predictable decision-making basis.

\section{ACKNOWLEDGEMENT}

This research was financially supported by Regional Industrial Economic Development Center of Chongqing College of Electronic Engineering (number: XJPT201710).

\section{REFERENCES}

[1] Zhu Li, Yu-ying Li, Management accounting and core competence in big data era, Finance and Accounting,2016(13).

[2] Xin-cheng Zhang, An analysis of the way to improve the quality of financial reports in the context of big data- based on accounting process reengineering, Communication of Finance and Accounting, 2017(4).

[3] Yong-mei Zhang,Ying Yu, Enterprise management accounting framework design in the internet plus model, Friends of Accounting, 2016(3) 